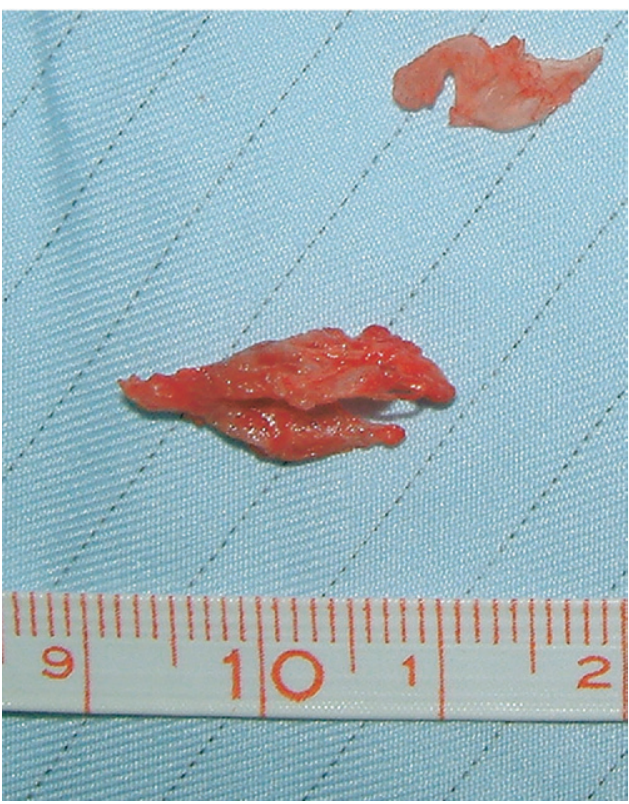

Figure 2. Fragments of glue extricated from aortic root (ruler scale in centimeters). persistent threat of embolization and potential frustration of the prosthetic valve with a beating heart after clamp removal.

De-airing of the heart after AVR using a standard, rigorous technique with aortic root and left ventricular vents creates transient conditions during which negative pressure and low, turbulent flows exist. These conditions may favor the aggregation of glue particles once inside the aorta in a similar fashion to conditions favoring thrombus formation as stated in Virchow's triad. ${ }^{5}$ We propose that even rapidly polymerizing cyanoacrylate glues should be used with caution at aortic suture lines and, in particular, that the timing of application with respect to de-airing using aortic root vents is critical.

\section{References}

1. Karimi M, Kerber RE, Everett JE. Mechanical aortic valve malfunction an intraoperative BioGlue complication. J Thorac Cardiovasc Surg. 2005; 129:1442-3.

2. Guerrero MA, Cox M, Lumsden AB, Reardon M, Howell J. Embolus of surgical adhesive to the extremities causing acute ischemia: report of two cases. J Vasc Surg. 2004;40:571-3.

3. Robicsek F, Rielly JP, Marroum MC. The use of cyanoacrylate adhesive (Krazy Glue) in cardiac surgery. J Card Surg. 1994;9:353-6.

4. Braunwald NS. A clinical evaluation of methyl-2-cyanoacrylate monomer as a hemostatic agent on the aorta. Ann Surg. 1966;164:967-72.

5. Lowe GD. Virchow's triad revisited: abnormal flow. Pathophysiol Haemost Thromb. 2003;33:455-7.

\title{
Mechanical valve obstruction caused by an occlusion device
}

\author{
Ofer Merin, MD, Dani Bitran, MD, Daniel Fink, MD, Esther Asher, MA, and Shuli Silberman, MD, Jerusalem, Israel
}

$\mathrm{M}$ echanical occlusion devices are used mainly for the closure of septal defects or patent ductus. There have been some reports of their use for the closure of paravalvular leaks after valve replacement. The potential for leaflet obstruction of a mechanical mitral prosthesis has so far been unrecognized. This is the first report of this potential complication.

\section{Clinical Summary}

A 74-year-old woman underwent coronary bypass and aortic valve replacement with a mechanical device 13 years ago. Two years

\footnotetext{
From the Department of Cardiothoracic Surgery, Shaare Zedek Medical Center, Jerusalem, Israel.

Received for publication Sept 27, 2006; accepted for publication Oct 30, 2006.

Address for reprints: Shuli Silberman, MD, Department of Cardiothoracic Surgery, Shaare Zedek Medical Center, PO Box 3235, Jerusalem, Israel 91031 (E-mail: ssilberman@ szmc.org.il).

J Thorac Cardiovasc Surg 2007;133:806-7

$0022-5223 / \$ 32.00$

Copyright $\odot 2007$ by The American Association for Thoracic Surgery doi:10.1016/j.jtcvs.2006.10.048
}

before the current admission, she underwent a second operation to replace her mitral valve because of heart failure secondary to severe mitral incompetence. Her valve was replaced with a St Jude 25-mm valve (St Jude Medical, St Paul, Minn). Shortly thereafter, shortness of breath developed in the patient, and a severe paravalvular leak was seen on the mitral prosthesis. She then underwent attempted closure of the paravalvular leak with percutaneous insertion of an Amplatzer occlusion device (AGA Medical Corporation, Golden Valley, Minn). Her condition continued to deteriorate, hemolytic anemia developed, and severe mitral regurgitation persisted (seen on echocardiography as an eccentric jet). Fluoroscopy (Figure 1) showed that 1 of the valve leaflets, adjacent to the device, was immobile. She was then referred to our department for repeat mitral valve replacement. The occlusion device was found to impinge on the posterior leaflet, restricting it in a closed position (Figure 2). The mitral valve was replaced with a bioprosthesis. The operation and immediate postoperative course were uneventful; however, on the day after surgery massive bleeding developed from the mediastinal drains. Emergency exploration was undertaken in the intensive care unit, which revealed bleeding from the area of the inferoposterior left ventricular wall, suggestive of atrioventricular rupture. The patient could not be resuscitated, and she died. Reexamination 


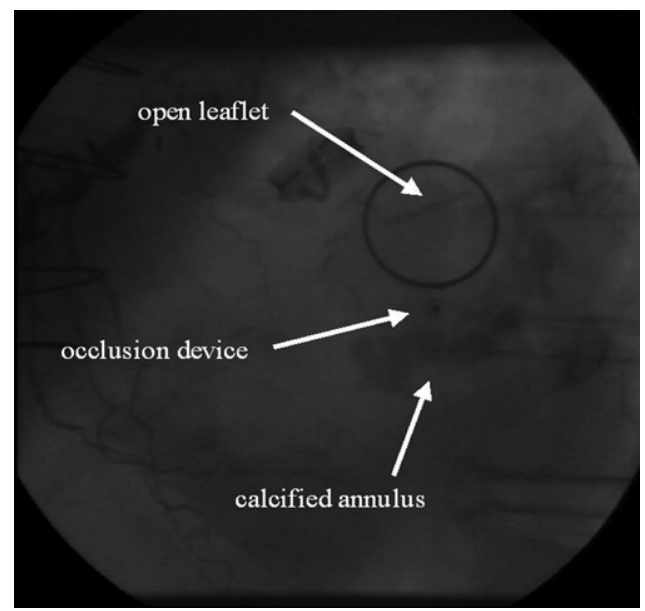

Figure 1. Mechanical mitral prosthesis with 1 leaflet visible in the open position. The other leaflet immobilized by the occlusion device cannot be visualized.

of the angiogram revealed a relatively large distance between the original mitral prosthesis and the calcified mitral annulus. This indicates that atrioventricular disruption may have been present before surgery but was contained because of adhesions; however, we could not be certain that the device directly contributed to the catastrophic event.

\section{Discussion}

Percutaneous insertion of occluding devices is used mainly for closure of intracardiac defects. Transcatheter closure of paravalvular leaks was first reported by Hourihan and colleagues ${ }^{1}$ in 1992. There have been other reports of the use of occlusion devices in the mitral position ${ }^{2}$ and aortic position. ${ }^{3}$

Pate and colleagues ${ }^{4}$ summarized the techniques and considerations of percutaneous device use for closure of prosthetic valve leaks. In their article they mention a number of potential device-related complications, such as valve dehiscence, device embolization, infection, wire trauma, valve leaflet damage, impingement of valve leaflet motion, and hemolysis. Hussain and colleagues $^{5}$ reported a case of attempted repair of paravalvular prosthetic mitral leak with an Amplatzer device (AGA Medical Corporation). The patient continued to demonstrate congestive heart failure and hemolysis secondary to persistent paravalvular leak and required surgery to remove the old prosthesis and the device.

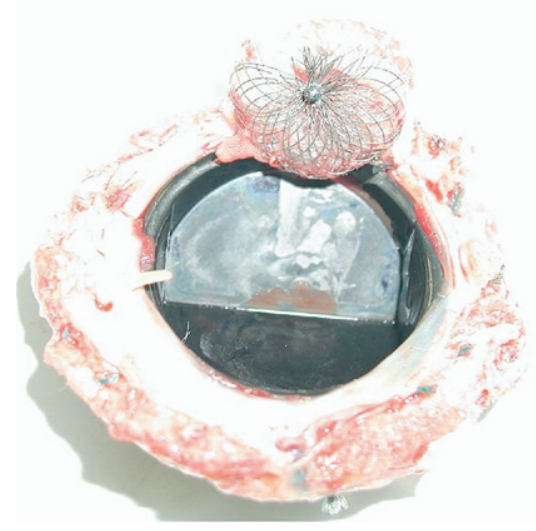

Figure 2. Explanted prosthetic valve with the occlusion device. The valve leaflet adjacent to the device was immobilized in the closed position.

Our patient presented with severe congestive heart failure and hemolysis. The intention of avoiding surgery was not realized. Furthermore, she underwent surgery in a compromised clinical state. Current devices are not geometrically adapted to the anatomy of paravalvular leaks. A device may successfully repair a small leak but also propagate valve dehiscence. We believe that paravalvular leaks are best treated with reoperation. At this time, the use of percutaneous occlusion devices for closure of paravalvular leaks should be limited to those patients who are not surgical candidates. To our knowledge, our case is the first report of a device impinging on the valve leaflet.

\section{References}

1. Hourihan M, Perry SB, Mandell VS, Keane JF, Rome JJ, Bittl JA, et al. Transcatheter umbrella closure of valvular and paravalvular leaks. $J$ Am Coll Cardiol. 1992;20:1371-7.

2. Kort HW, Sharkey AM, Balzer DT. Novel use of the Amplatzer duct occluder to close perivalvular leak involving a prosthetic mitral valve. Catheter Cardiovasc Interv. 2004;61:548-51.

3. Webb JG, Pate GE, Munt BI. Percutaneous closure of an aortic prosthetic paravalvular leak with an Amplatzer duct occluder. Catheter Cardiovasc Interv. 2005;65:69-72.

4. Pate GE, Thompson CR, Munt BI, Webb JG. Techniques for percutaneous closure of prosthetic paravalvular leaks. Catheter Cardiovasc Interv. 2006;67:158-66.

5. Hussain ST, Devagourou V, Kumar AS. Management of mitral paravalvular leak: therapy or misadventure? J Thorac Cardiovasc Surg. 2003;126:879-80. 